\title{
Formação Docente na Pós-Graduação Stricto Sensu em Ciência da Computação: um recorte das regiões Norte e Nordeste
}

\author{
Pauleany S. Morais', Jean C. S. Rosa ${ }^{2}$, Anna Raquel S. Marinho ${ }^{3}$, Ecivaldo Matos² \\ ${ }^{1}$ Campus de Educação a Distância - Instituto Federal do Rio Grande do Norte (IFRN) \\ Natal - Rio Grande do Norte - Brasil \\ ${ }^{2}$ Departamento de Ciência da Computação - Universidade Federal da Bahia (UFBA) \\ Salvador - Bahia - Brasil \\ ${ }^{3}$ Campus Zona Norte - Instituto Federal do Rio Grande do Norte (IFRN) \\ Natal - Rio Grande do Norte - Brasil \\ pauleany.morais@ifrn.edu.br, jean.rosa@ufba.br, \\ raquelmarinho.linfor@gmail.com, ecivaldo@ufba.br
}

\begin{abstract}
Resumo. A formação docente necessária aos professores que atuam/atuarão no sistema de ensino superior brasileiro está presente em inúmeras discussões acadêmicas. Nesse sentido, este artigo apresenta resultados de uma investigação sobre as iniciativas de formação docente nos cursos de pós-graduação stricto sensu em Ciência Computação de instituições federais de ensino superior das regiões Norte e Nordeste do Brasil. Para isso foi realizada a análise de documentação dos cursos de mestrados e doutorados acadêmicos. Identificou-se que determinados cursos de pós-graduação tentam sanar essa limitação de formação docente por meio de disciplinas sobre didática no ensino superior, alguns implementam atividades como estágio docente e outros não possuem quaisquer iniciativas voltadas à formação docente dos seus estudantes.
\end{abstract}

\begin{abstract}
There are several scientific studies about the Brazilian teacher training for higher education. In this sense, this paper presents results of an investigation about the initiatives of teacher training in Computer Science graduate programs of federal higher education institutions of North and Northeast of Brazil. For this, one documentary analysis on pedagogical documentos of that programs was carried out. It was identified that a few graduate courses (master's and doctoral) have some targeted actions for teacher training, with disciplines on didactics in higher education or activities of supervised teaching internship. The most programs do not have any initiative aimed at teacher training of their students.
\end{abstract}

\section{Introdução}

A formação de professores tem enfrentado grandes desafios ao longo dos anos, principalmente no que se refere ao exercício da docência por bacharéis e tecnólogos nas diversas modalidades de ensino. Pimenta e Anastasiou (2014) apresentam estudos sobre 
as especificidades da Docência no Ensino Superior com concreta vivência da ensinagem. Destacam a relevância da compreensão do processo de ensinagem e seleção de determinadas estratégias necessárias à atuação docente, particularmente, no Ensino Superior.

Para Imbernón (2012), o professor do Ensino Superior deve conscientizar-se da necessidade de dominar conhecimentos didáticos em sua área de atuação e sua interação com a disciplina, a própria docência e as interações vivenciadas junto aos discentes. No Brasil, a formação docente para o Ensino Superior ocorre na formação em nível de pós-graduação stricto sensu (mestrados e doutorados acadêmicos) (BRASIL, 1965).

No entanto, na área de Ciência da Computação, de modo geral, os programas de pós-graduação (PPG) em Ciência da Computação no Brasil não possuem políticas de formação de professores para além de ações pontuais, como a instituição de estágio (ou tirocínio) docente, ou disciplinas optativas de Metodologia do Ensino Superior (ou Didática do Ensino Superior) (MASSA, 2015).

De maneira geral, observa-se que os professores bacharéis e tecnólogos condicionam sua atuação profissional docente às experiências vivenciadas como alunos. Essa atitude é típica dos professores sem formação pedagógica específica, assim como ocorre no ensino de computação na Educação Profissional (SILVA, MATOS e MASSA, 2018). Tal condição pode desqualificar o ato educativo diante da incompletude das exigências necessárias à docência. De acordo com Reche e Vasconcelos (2014), as situações educacionais necessitam de uma tomada de posição do professor. Nesse contexto, o professor não licenciado possivelmente não vivenciou possibilidades de formação inicial que exigissem posicionamentos em ensaios de práticas educacionais.

Este artigo apresenta uma reflexão sobre a necessidade de formação docente nos PPG que atendam às exigências específicas do Ensino Superior e práticas curriculares condizentes ao ensino de Ciência da Computação com qualidade. Além disso, também são apresentados resultados de análise documental sobre os objetivos dos cursos de pós-graduação em Ciência da Computação e as suas iniciativas de formação docente. Dada a dimensão territorial do Brasil, bem como o número de PPG na área, realizou-se um recorte nas Regiões Norte e Nordeste do país.

$\mathrm{Na}$ próxima seção, serão tratados os significados da formação profissional docente no Ensino Superior. Na Seção 3 enfatiza-se as diretrizes normativas e os mecanismos para formação docente no Ensino Superior nos PPG de Ciência da Computação em Instituições Federais de Ensino Superior do Norte e do Nordeste. A Seção 4 é destinada à apresentação da metodologia de pesquisa e as Seções 5 e 6 , respectivamente, tratam sobre os resultados identificados e as considerações finais.

\section{Significados da Formação Profissional Docente no Ensino Superior}

A formação profissional docente representa um processo em que o sujeito constrói um conhecimento pedagógico especializado que deve ser vivenciado no espaço das instituições formadoras ou mesmo orientado por elas. Os estudos que investigam essa formação mostram que o foco do exercício profissional docente deve estar na realidade social, devido à intensa relevância do processo ação-reflexão-ação (RAMALHO; NUÑEZ; GAUTHIER, 2003). 
Para alcançar a formação profissional, o projeto de formação de professores deve articular de maneira integrada o exercício da profissão do magistério, a formação continuada, as atividades de pesquisas pedagógicas e as atividades de pesquisas colaborativas, enquanto processos constantes, necessariamente refletidos e questionáveis que possibilite a formação do professor como agente social (VEIGA, 2002). De maneira geral, o pensamento que se tenta realçar até essas linhas pode ser traduzido por meio da Figura 1, pois ilustra essa proposição de acordo com os estudos de Veiga (2002, p. 30):

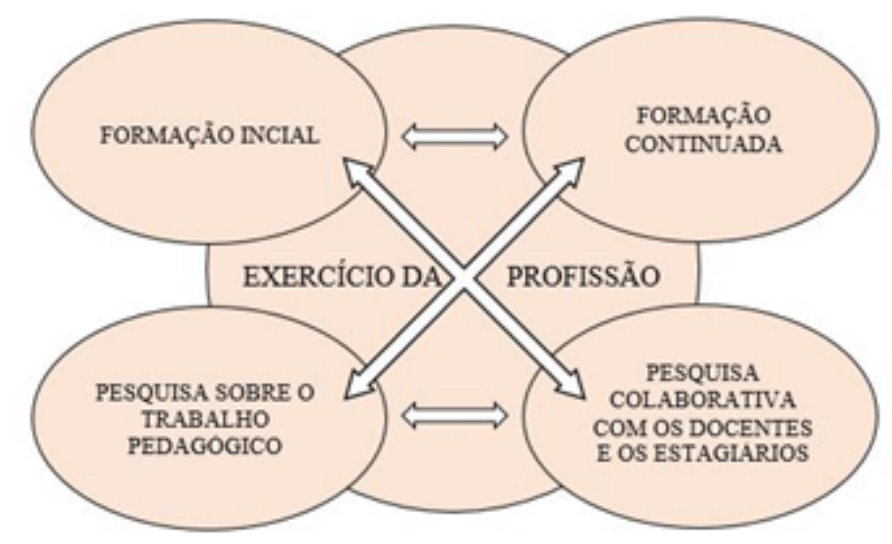

Figura 1. Modelo de formação profissional do professor como agente social (fonte: VEIGA, 2002).

Nessa compreensão, pode-se dizer que a formação centrada na práxis envolve todas as condições necessárias ao desenvolvimento de programas de formação, pois é o campo empírico que por excelência proporciona respostas às demandas da própria instituição, como a elevação da qualidade do ensino e da aprendizagem em sala de aula, bem como deve ser o campo empírico para responder às necessidades das instituições superiores (IMBERNÓN, 2004). Isto é, formação profissional com foco nos saberes da experiência no próprio fazer pedagógico.

Esse profissional deve refletir sobre a sua prática didática, pesquisando os elementos da ação docente nos próprios contextos nos quais ocorrem, no sentido de qualificar o ato de ensinar e de aprender (PIMENTA; GHENDIN, 2002). Defende-se que a formação docente possa preparar os sujeitos em suas múltiplas dimensões para atuação profissional qualificada, assim fazê-los vivenciar o termo "dodiscência" (docência-discência), no sentido de representar a relação dialética entre ensinar e aprender (FREIRE, 1996).

O repensar da práxis do professor requer espaços para que ele possa experienciar o conhecimento em suas várias possibilidades, tornando-se pesquisador de sua própria prática, construindo um olhar crítico e intencional reflexivo sobre ela (PIMENTA; GHEDIN, 2002). Esse processo de fortalecimento da prática de ensino, considera que o fazer pedagógico do professor-aluno não é linear, mas gradual, envolvendo avanços, recuos, conflitos, desequilíbrios, encontros e desencontros. A constituição dos saberes necessários à docência no Ensino Superior precisa ser vivenciada na formação em nível 
pós-graduação, pois as universidades têm intensa responsabilidade em oferecer à sociedade profissionais que tenham habilidades e competências para utilizar o conhecimento abstrato em situações do concreto real em atuação profissional (IMBERNÓN, 2012).

Sendo assim, é imprescindível que o sujeito mesmo sem formação pedagógica específica e que se dispõe a ser professor, tenha possibilidades de compartilhar momentos de discussões teóricos e experienciais em processos de ensinagem (PIMENTA; ANASTASIOU, 2014); sejam em formação inicial ou continuada. Dessa maneira, o sujeito que pretende atuar como professor, ainda que não tenha formação em curso de licenciatura, precisa ser sensibilizado a compreender as nuances do fazer didático-pedagógico exigido para e na educação.

No Ensino Superior, conforme sinalizam Pimenta e Anastasiou (2014), pode-se utilizar diversas estratégias para condução da ensinagem, tais como: a aula expositiva dialogada, o estudo de texto, o portfólio, a tempestade cerebral, o mapa conceitual, o estudo dirigido, a lista de discussão por meios informatizados, a solução de problemas, o grupo de verbalização e de observação, a dramatização, o seminário, o estudo de caso, o júri simulado, o simpósio, o painel, o fórum, a oficina, o estudo do meio, o ensino com pesquisa, dentre outros. Apesar da utilização das referidas estratégias, não se pode deixar de definir objetivos de ensino para cada uma delas, pois essas não podem operacionalizadas como fins em si mesmas. As autoras apresentam essas possibilidades de estratégias no sentido de viabilizar o processo de ensinagem e superar perspectivas tradicionais de ensino.

No caso da atuação profissional no ensino superior de Ciência da Computação, a formação docente tem a necessidade de refletir sobre o desenvolvimento do computational thinking (pensamento e/ou raciocínio computacional) (FERREIRA et al., 2015) atrelado a processos educacionais nos diversos níveis e modalidades da educação. $\mathrm{Na}$ discussão sobre computational thinking, Wing (2006) refere-se às diversas possibilidades analíticas da Computação. Desse modo, o conceito defendido pela autora relaciona-se ao potencial da Ciência da Computação diante das necessidades de resolução de problemas, abstração, decomposição, automação, simulação, modelação, pensamento recursivo, seqüencial e paralelo. Mostra-se a relevância dos estudos sobre raciocínio computacional significativo à resolução de problemas do cotidiano.

Com intenso potencial de articular ações, discussões e debates das diversas áreas do conhecimento, o desenvolvimento do raciocínio computacional (FERREIRA et al, 2015) deveria ser uma busca constante em processos educacionais orientadores da prática docente em Ciência da Computação. Isso significa inferir que a prática docente necessita de encaminhamentos pedagógicos, didáticos, metodológicos e conceituais na sistematização dos conhecimentos científicos próprios da Ciência da Computação. No entanto, o percurso profissional docente dos que atuam na Ciência da Computação em diversos níveis ou modalidades de ensino não contempla a formação em cursos de licenciatura, com restrita ou total ausência de significativas possibilidades de formação pedagógica que discutam ou os orientem a adequação comportamental, conceitual ou metodológica voltadas ao processo educacional (MASSA, 2015).

Oliveira e Silva (2012, p. 196) concluem que o "[...] bacharel torna-se professor sem nenhum tipo de formação pedagógica e os licenciados, por sua vez, assumem a 
profissão com lacunas em seu processo formativo". Portanto, a formação ao Ensino de Ciência da Computação, vivência problemáticas que se baseiam na ausência de qualquer orientação didático-pedagógica mais ampla sobre o ato de ensinar e aprender. Matos (2013) analisa que a Computação ao longo de sua história possui restrita tradição em estudar aspectos identitários de seus profissionais. Por consequência, tem-se exigido formação cada vez mais especializada dos profissionais, e dos que atuam na docência (bacharéis, tecnólogos e/ou licenciados) uma qualificação pedagógica e formação técnica condizente à área da Ciência da Computação (MATOS, 2013).

O percurso profissional docente dos que atuam na Computação geralmente não está articulado à uma formação pedagógica e conhecimentos conceituais das áreas específicas exigidos à docência (SANTOS; SANTOS, 2012). A formação de professores de uma maneira geral precisa mobilizar conhecimentos epistemológicos de determinada área científica, didático-pedagógico e situações de aprendizagem reais que podem consolidar a constituição dos saberes docentes - formação profissional, disciplinares, curriculares e experienciais (TARDIF, 2012).

Massa (2015) trata da formação pedagógica para o ensino de Ciência da Computação e constata que muito se tem pesquisado sobre o tema da Informática na Educação quando se refere à utilização de novas Tecnologias de Informação e Comunicação (TIC). No entanto, alerta para a existência de poucas pesquisas brasileiras sobre a educação relacionada às questões específicas do processo de ensino e de aprendizagem de Ciência da Computação. Mostra-se, portanto, cada vez mais a necessidade dos PPG em Ciência da Computação se preocuparem com a formação docente de seus alunos.

\section{Diretrizes para formação docente na pós-graduação em Ciência Computação}

No sentido de compreender as possibilidades de formação docente nos PPG em Ciência da Computação se faz necessário analisar as orientações normativas que amparam as ações pedagógicas dos PPG no Brasil. A formação dos sujeitos que tomam posição pela docência mesmo não sendo formados em cursos de licenciatura em computação (a maioria dos profissionais docentes na/da Ciência da Computação), confere às instituições educacionais em nível superior intensa responsabilidade de desenvolver formação continuada para exercício do magistério.

O artigo 66 da Lei de Diretrizes e Bases da Educação Nacional - LDB (BRASIL, 1996) prescreve que a preparação para o exercício do magistério no ensino superior deve ser realizada em nível de pós-graduação, prioritariamente, em programas de mestrado e doutorado.

No ano de 2010, instituiu-se o Plano Nacional de pós-graduação - PNG (2011-2020), oriundo de comissões compostas por representantes de universidades públicas brasileiras com notoriedade nacional para constituir eixos norteadores aos PPG. O sistema de pós-graduação brasileiro foi implantado a partir dos anos 1970, amparado no arcabouço jurídico da Reforma Universitária de 1968. Esse sistema seguiu o modelo de universidade estadunidense, com a missão de promover formação de professores e de pesquisadores (BRASIL, 2010). Desse modo, desde sua origem, os programas deveriam instituir ações que contemplassem a formação para docência e para pesquisa. 
O PNG (2011-2020) foi articulado em cinco eixos que deveriam conduzir as ações dos PPG em todo o país, como segue abaixo:

1 - a expansão do Sistema Nacional de pós-graduação (SNPG), a primazia da qualidade, a quebra da endogenia e a atenção à redução das assimetrias; 2 - a criação de uma nova agenda nacional de pesquisa e sua associação com a pós-graduação; 3 - o aperfeiçoamento da avaliação e sua expansão para outros segmentos do sistema de C,T\&I; 4 - a multi- e a interdisciplinaridade entre as principais características da pós-graduação e importantes temas da pesquisa; 5 - o apoio à educação básica e a outros níveis e modalidades de ensino, especialmente o ensino médio (BRASIL, 2010, p. 15).

Observa-se na delimitação dos eixos, a inexistência de um item que contemple a formação docente ao Ensino Superior, tendo maior ênfase na formação para a pesquisa. Certamente essa ausência da discussão da formação de professores destinada ao Ensino Superior necessária aos PPG, gera fundamentos para possíveis estudos científicos, conforme afirma Massa (2015).

Isto posto, tem-se na pós-graduação brasileira ênfase na formação de desenvolvimento da pesquisa no país. No entanto, como formar bom pesquisadores sem bons professores? Algo bastante contraditório. Portanto, há intensa necessidade de o professor universitário conscientizar-se da importância dos estudos didáticos para melhorar sua relação com os conhecimentos que devem ser sistematizados, sua relação com a disciplina, com os alunos e com sua própria docência (IMBERNÓN, 2012).

Aspecto significativo destacado no PNG é a necessidade de a CAPES (BRASIL, 2010) articular ações educacionais de apoio às diversas modalidades de ensino, particularmente, a educação básica. Na abertura da terceira semana de Avaliação Trienal no ano de 2013, a diretora de Formação de Professores da Educação Básica da CAPES, Carmem Moreira de Castro Neves, falou sobre a urgente necessidade de articulação entre a pós-graduação e a educação básica, segundo a Coordenação de Comunicação Social da Capes (BRASIL, 2014). Ela avalia, ainda, que a pós-graduação no Brasil não pode ter números consideráveis se a qualidade da educação básica for insatisfatória (BRASIL, 2014). Essas notícias evidenciam a preocupação e as orientações normativas que indicam a considerável relevância de articulação sistêmica entre os níveis de educação do nosso país para elevação do padrão de qualidade como um todo do sistema educacional.

O Documento de Área de Ciência da Computação da CAPES do ano quadriênio 2013-2016 (BRASIL, 2016) evidencia a preocupação com a natureza interdisciplinar da área e suas possíveis contribuições ao Ensinos Fundamental e Médio. Nesse caso, os PPG em Ciência da Computação precisam oferecer formação para docência de modo interdisciplinar, bem como subsídios de pesquisa e extensão em outros níveis de ensino para alcance das diretrizes estabelecidas nos documentos oficiais divulgados pela própria CAPES. 
Compreende-se que as diretrizes instituídas nos documentos não contempla de maneira incisiva a formação docente, mas a condução de pesquisas científicas. Neste artigo, não se busca desvalorizar a formação para/em pesquisa na pós-graduação, mas refletir sobre a relevância da formação docente no Ensino Superior, particularmente na área de Ciência da Computação. Desse modo, os documentos oficiais são primordiais para a análise dos objetivos dos PPG, pois orientam as diretrizes postas e evidencia a ausência de políticas de formação de professores para compreensão de suas especificidades.

A ausência de formação pedagógica dos professores no Ensino Superior também pode ser relacionada ao tratamento opcional dos componentes curriculares de formação docente, conforme observado nos documentos. Nesse caso, o professor universitário sem formação pedagógica restringe suas possibilidades de reflexão e ação sobre aspectos sociais, psicológicos e pedagógicos do seu trabalho profissional específico ao ensino superior (IMBERNÓN, 2012).

De acordo com a CAPES ${ }^{1}$, o Parecer MEC/CESu no 977/65 (BRASIL, 1965) é o marco conceitual e regulatório da pós-graduação brasileira. O parecer define e confere os objetivos dos cursos de pós-graduação stricto sensu no Brasil. De acordo com o parecer, é imperativo que os cursos de pós-graduação stricto sensu formem professores universitários, haja vista que o primeiro objetivo dos PPG, segundo o parecer, é "formar professorado competente que possa atender à expansão quantitativa do nosso ensino superior garantindo, ao mesmo tempo, a elevação dos atuais níveis de qualidade" (BRASIL, 1965; p. 3). Essa necessidade de formação de professores do nível superior evidenciada pelo parecer, está relacionada à falta de profissionais docentes qualificados. Portanto, conforme o parecer, o instrumento fundamental para a formação dos professores do ensino superior são os cursos de pós-graduação stricto sensu (BRASIL, 1965).

Com bases nessas reflexões e regulações oficiais sobre a formação docente na pós-graduação stricto sensu em Ciência da Computação, questiona-se sobre quais são as iniciativas de formação docente nos PPG em Ciência da Computação no Brasil e como essas iniciativas se relacionam com os objetivos desses PPG? Essa questão norteou a pesquisa apresentada nesse artigo, que apresenta resultados sobre a ações voltadas à formação docente para o ensino superior nos PPG de Ciência da Computação de instituições federais de ensino superior das Regiões Norte e Nordeste.

\section{Metodologia}

Para identificar as iniciativas de formação docente nos cursos de pós-graduação stricto sensu em Ciência Computação foi realizada uma pesquisa documental nos documentos oficiais dos programas de pós-graduação de instituições federais de ensino superior das Regiões Norte e Nordeste do Brasil avaliados pela CAPES na área de Ciência da Computação.

A pesquisa documental consiste na análise de documentos ou dados na busca de informações e de padrões que possam contribuir para a resolução de um determinado

\footnotetext{
1 Disponível em: http://capes.gov.br/avaliacao/sobre-a-avaliacao/legislacao-especifica. Acesso em: $31 / 03 / 2018$
} 
problema (WAZLAWICK, 2010). Portanto, foram investigados os regimentos e matrizes curriculares dos respectivos cursos.

Para guiar a análise foram concebidas sete questões a serem respondidas com base na análise dos documentos:

Q1 - Qual é o objetivo do programa de pós-graduação?

Q2 - O programa de pós-graduação oferece alguma disciplina voltada à formação docente?

\section{Q2.1 - Qual é o título dessa disciplina?}

Q2.2 - Essa disciplina é de caráter obrigatório?

Q3 - O programa de pós-graduação oferece alguma atividade curricular voltada à formação docente (ex.: estágio docente)?

Q3.1 - Quais são os tipos de atividades?

Q3.2 - Essas atividades são de caráter obrigatórias?

De acordo com o Documento de Área da Ciência da Computação, publicado pela CAPES em 2016, há 109 cursos de pós-graduação stricto sensu na área de Ciência da Computação (BRASIL, 2016). Desse quantitativo, a Região Nordeste possui 29 programas de pós-graduação e a Região Norte possui apenas três ${ }^{2}$.

Dentre os 32 programas de pós-graduação das Regiões Norte e Nordeste, foram excluídos os programas de instituições privadas e estaduais de ensino superior e programas/cursos de mestrado profissional, reduzindo a amostra para a análise à quantidade de 15 programas. O Quadro 1. apresenta os nomes dos programas, as instituições federais de ensino superior vinculadas e os níveis dos cursos ofertados (mestrado/doutorado), corpus de investigação dessa pesquisa.

Quadro 1. Programas de pós-graduação investigados.

\begin{tabular}{|l|l|c|}
\hline \multicolumn{1}{|c|}{ Nome } & \multicolumn{1}{|c|}{ Instituição de Ensino Superior } & Tipo \\
\hline Informática & Universidade Federal de Alagoas (UFAL) & $\mathrm{M}^{3}$ \\
\hline Informática & Universidade Federal do Amazonas (UFAM) & $\mathrm{MD}^{4}$ \\
\hline Ciência da Computação & Universidade Federal da Bahia (UFBA) & MD \\
\hline Ciência da Computação & Instituto Federal de Educação, Ciência e Tecnologia do Ceará (IFCE) & $\mathrm{M}$ \\
\hline $\begin{array}{l}\text { Ciências da } \\
\text { Computação }\end{array}$ & Universidade Federal do Ceará (UFC) & $\mathrm{MD}$ \\
\hline Ciência da Computação & Universidade Federal do Maranhão (UFMA) & $\mathrm{M}$ \\
\hline Ciência da Computação & Universidade Federal do Pará (UFPA) & MD \\
\hline Ciência da Computação & Universidade Federal de Campina Grande (UFCG) & MD \\
\hline
\end{tabular}

${ }^{2}$ Esse dados foram coletados na Plataforma Sucupira. $\quad$ Disponível em:
https://sucupira.capes.gov.br/sucupira/ Acesso em: 19/02/2018.

${ }^{3}$ Mestrado.

${ }^{4}$ Mestrado e Doutorado. 


\begin{tabular}{|l|l|c|}
\hline Informática & Universidade Federal da Paraíba (UFPB) & $\mathrm{M}$ \\
\hline $\begin{array}{l}\text { Ciências da } \\
\text { Computação }\end{array}$ & Universidade Federal de Pernambuco (UFPE) & $\mathrm{MD}$ \\
\hline Informática Aplicada & Universidade Federal Rural de Pernambuco (UFRPE) & $\mathrm{M}$ \\
\hline Ciência da Computação & Universidade Federal do Piauí (UFPI) & $\mathrm{M}$ \\
\hline Ciência da Computação & $\begin{array}{l}\text { Universidade Estadual do Rio Grande do Norte \& Universidade } \\
\text { Federal Rural do Semi-Árido } \text { (UERN-UFERSA) }\end{array}$ & $\mathrm{M}$ \\
\hline Sistemas e Computação & Universidade Federal do Rio Grande do Norte (UFRN) & $\mathrm{MD}$ \\
\hline Ciência da Computação & Universidade Federal de Sergipe (UFS) & $\mathrm{M}$ \\
\hline
\end{tabular}

\section{Resultados}

Foram identificados e analisados os regimentos e as matrizes curriculares dos 15 PPG da área de Ciência da Computação de instituições federais de ensino superior das Regiões Norte e Nordeste do Brasil.

Para favorecer a compreensão dos objetivos dos PPG foi criada a tagcloud apresentada na Figura 2. A tagcloud foi composta pelas palavras que compõem os objetivos dos PPG corpus desta pesquisa. Acredita-se que a evidência das palavras em conjunto podem apontar a associação de termos e fornecer os interesses e experiências das palavras investigadas; impressão geral do conjunto de conteúdo (Rivadeneira et al., 2007).

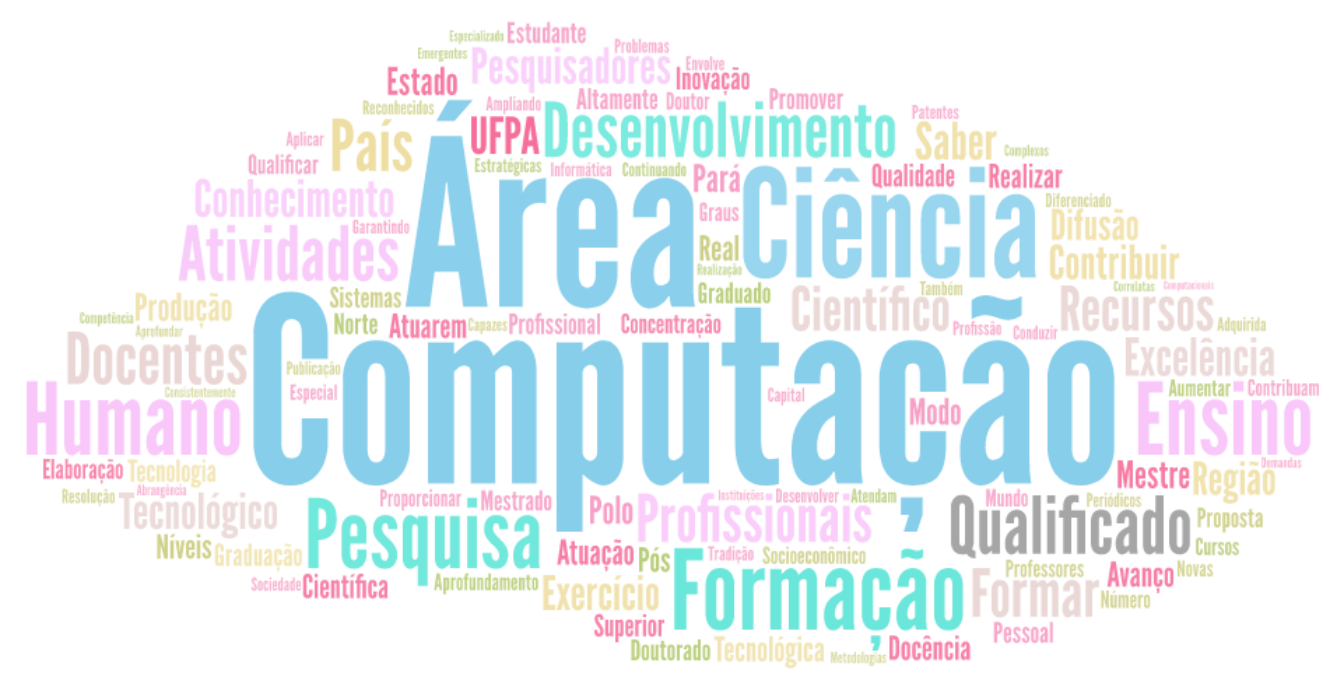

Figura 2. Tagcloud de palavras que compõem os objetivos dos PPG em Ciência da Computação das Regiões Norte e Nordeste.

Nessa tagcloud as palavras "computação", "ciência" e "área” estão em evidência com relação às demais, isso acontece porque houve 16 ocorrências da palavra "computação" e 14 das palavras "ciência" e "área". Todavia, o que interessa a esta

\footnotetext{
${ }^{5}$ O PPG em Ciência da Computação da UERN-UFERSA é multi-institucional com associação ampla entre as duas instituições e por uma delas ser federal, o programa foi incluído (cf. https://ppgcc.ufersa.edu.br/apresentacao/).
} 
pesquisa é o destaque das palavras relacionadas à atividade docente (i.e. ensino, docentes, docência, professores). Dentre as relacionadas à formação docente, a palavra "ensino" é a de maior destaque. Todavia, várias outras palavras estão mais destacadas que às palavras relacionadas a atividade docente e isso expressa a importância dada pelos PPG, por exemplo, à "pesquisa" quando comparada ao "ensino".

A palavra "pesquisa" está mais evidente que a palavra "ensino", isso acontece porque somente nove dos 15 PPG tratam sobre a formação de professores em seus objetivos. Portanto, é possível reconhecer que os objetivos dos PPG estão mais alinhados à formação e desenvolvimento de pesquisadores e/ou pesquisas na área de Ciência da Computação, deixando de lado o primeiro objetivo da pós-graduação apresentado pelo Parecer MEC/CESu no 977/65, a formação do professor do ensino superior (BRASIL, 1965).

O Quadro 2 apresenta a sumarização dos dados coletados quanto à formação docente dos pós-graduandos na área de Ciência da Computação. Por meio da análise documental foi possível identificar que somente três PPG oferecem disciplinas relacionadas à docência no ensino superior: UFRN, UFCG e IFCE.

Quadro 2. Sumarização dos dados coletados ${ }^{6}$.

\begin{tabular}{|c|c|c|c|c|c|c|}
\hline Instituição & Q2 & Q2.1 & Q2.2 & Q3 & Q3.1 & Q3.2 \\
\hline UFAL & Não & -- & -- & Sim & Estágio Docência & $\begin{array}{c}\text { Somente para } \\
\text { bolsistas CAPES }\end{array}$ \\
\hline UFAM & Não & -- & -- & Sim & Estágio Docência & Para todos alunos \\
\hline UFBA & Não & -- & -- & Sim & $\begin{array}{c}\text { Estágio Docente } \\
\text { Supervisionado }\end{array}$ & Para todos alunos \\
\hline IFCE & Sim & $\begin{array}{c}\text { Docência no } \\
\text { Ensino Superior }\end{array}$ & Não & Não & -- & - \\
\hline UFC & Não & -- & -- & Não & -- & -- \\
\hline UFMA & Não & -- & -- & Não & -- & -- \\
\hline UFPA & Não & -- & -- & Sim & $\begin{array}{c}\text { Estádio de } \\
\text { Docência }\end{array}$ & $\begin{array}{c}\text { Para mestrandos } \\
\text { bolsistas e para } \\
\text { todos } \\
\text { doutorandos }\end{array}$ \\
\hline UFCG & Sim & $\begin{array}{l}\text { Metodologia do } \\
\text { Ensino Superior }\end{array}$ & Não & Sim & Estágio Docência & Não \\
\hline UFPB & Não & -- & -- & Sim & Estágio Docência & Não \\
\hline UFPE & Não & -- & -- & Não & -- & -- \\
\hline UFRPE & Não & -- & -- & Sim & $\begin{array}{c}\text { Estágio de } \\
\text { Docência }\end{array}$ & Não \\
\hline UFPI & Não & -- & -- & Sim & Estágio Docência & Para todos alunos \\
\hline UERN-UFERSA & Não & -- & -- & Não & - & - \\
\hline
\end{tabular}

\footnotetext{
${ }^{6}$ Cada coluna faz referência à respectiva questão apresentada na metodologia.
} 


\begin{tabular}{|c|c|c|c|c|c|c|}
\hline UFRN & Sim & $\begin{array}{c}\text { Iniciação a } \\
\text { Docência no } \\
\text { Ensino Superior }\end{array}$ & $\begin{array}{c}\text { Somente para } \\
\text { bolsistas do } \\
\text { Programa de } \\
\text { Bolsas REUNI }\end{array}$ & Sim & $\begin{array}{c}\text { Estágio Docência } \\
\text { em Computação }\end{array}$ & $\begin{array}{c}\text { Somente para } \\
\text { bolsistas } \\
\text { Programa de } \\
\text { Bolsas REUNI }\end{array}$ \\
\hline UFS & Não & -- & -- & Sim & Estágio Docência & Para bolsistas \\
\hline
\end{tabular}

Na UFRN a disciplina oferecida é nominada de Introdução a Docência no Ensino Superior. A disciplina é de natureza obrigatória somente aos alunos bolsistas do Programa de Bolsas de Assistência ao Ensino do REUNI ${ }^{7}$. Por sua vez, na UFCG, a disciplina correlata é chamada de Metodologia do Ensino Superior e tem caráter optativo. No IFCE, a disciplina oferecida possui o nome Docência no Ensino Superior e também é de natureza optativa.

Apesar de muitos PPG não possuírem disciplinas relacionadas à formação docente em suas estruturas curriculares, dez PPG instituíram a atividade de estágio docente $^{8}$. Os PPG da UFAM e UFBA, que possuem cursos de mestrado e doutorado, estabeleceram o estágio docente como atividade obrigatória para ambos os cursos. A UFPA $^{9}$ institui o estágio docente como atividade obrigatória apenas para o doutorado, enquanto a UFPI apenas para o curso de mestrado.

Por sua vez, os PGG da UFAL, da UFS, ambos apenas com curso de mestrado, e o da UFRN tornaram obrigatório o estágio docente, mas apenas para os seus alunos bolsistas. O PPG da UFS ainda determinou que o aluno que comprovar o exercício de atividades de docência no ensino superior realizadas na própria UFS receberá créditos e, consequentemente, terá a quantidade de disciplinas a serem cursadas diminuída. Não foram encontrados dados sobre disciplinas ou atividades relacionadas à formação docente no ensino superior nos regulamentos e matrizes curriculares dos PPG da UFC, da UFMA, da UERN-UFERSA e da UFPE.

Dentre os programas estudados, o PPG da UFPE é o único com conceito 7 (excelência internacional) na última avaliação da CAPES (Quadriênio 2013-2016). Entretanto, esse programa não apresenta qualquer ação/atividade voltada à formação docente do ensino superior em seu regimento, nem na sua matriz curricular. Isso, de certo modo, reflete a desatenção dada pelo Comitê de Área da Ciência da Computação (BRASIL, 2016) à formação de professor para o ensino superior, conforme o objetivo do Parecer MEC/CESu no 977/65 (BRASIL, 1965).

Como afirma D’Ávila (2013), a atividade docente deve ser constituída em uma prática social ampla, com a combinação de conhecimentos, habilidades e atitudes, expectativas e percepções de mundo relacionadas a diversas histórias de vida dos professores. Nesse caso, os processos de ensinagem no Ensino Superior exigem reflexão sobre a prática social e coletiva diante da construção de um partilhar das próprias incertezas e dificuldades do ato de ensinar (PIMENTA e ANASTASIOU, 2014). Certamente, as restritas discussões promovidas no sentido de oferecer formação didático-pedagógica no Ensino Superior nos PPG de Ciência da Computação pouco

\footnotetext{
${ }^{7}$ Programa de Bolsas de Assistência ao Ensino do REUNI tem por objetivo elevar a qualidade do ensino superior público prestando subsídio aos cursos de graduação por meio dos cursos de pós-graduação.

${ }^{8} \mathrm{O}$ nome da atividade difere entre algumas instituições.

${ }^{9}$ No PPG da UFPA o estágio docente é obrigatório para bolsistas de mestrado.
} 
contribuirão para os professores compreenderem seu papel de agente social em sua atuação profissional (VEIGA, 2002). Por isso, as reflexões sobre a prática docente poderiam ocorrer em formações no transcurso dos mestrados e doutorados, de modo que principalmente os professores universitários bacharéis e tecnólogos (sem formação em licenciatura) tivessem melhores condições de refletir sobre suas práticas docentes.

\section{Considerações Finais}

A ausência de formação docente nos PPG em Ciência da Computação, nas regiões Norte e Nordeste do Brasil, tem repercussão não somente no Ensino Superior, mas nas demais modalidades de ensino. Sabendo que os profissionais formados em nível de pós-graduação poderão atuar e articular pesquisas em diversas modalidade de ensino, mesmo com intenso foco no ensino superior.

$\mathrm{O}$ intenso foco na pesquisa tem deixado a formação à docência em muitos casos na dimensão da opcionalidade, quando pelo menos isso é permitido. É contraditório o professor atuante no ensino superior apenas ter sua formação de pós-graduação direcionada à pesquisa. Mesmo porque a atuação docente exige a constituição de diversos saberes necessários à docência. O exercício profissional docente necessita ter movimentos que promovam processos de ação-reflexão-ação (RAMALHO; NUÑEZ; GAUTHIER, 2003) sobre o processo de ensinagem no Ensino Superior.

A pesquisa de Massa (2015), diante dos restritos estudos nessa área, mostra a necessidade de busca por formações de docência relacionadas ao ensino superior de Ciência da Computação. Precisa-se promover, sejam em disciplinas ou estudos, as reflexões necessárias sobre a atividade docente para ensinagem no ensino superior de modo mais amplo (PIMENTA e ANASTASIOU, 2014). E, para além disso, atender aos objetivos da pós-graduação stricto sensu no Brasil, conforme Parecer MEC/CESu n ${ }^{\circ}$ 977/65 (BRASIL, 1965).

Como enfatizado, na Figura 2 fica evidente a palavra "pesquisa" em detrimento do "ensino"; tal constatação é um dos indicativos das limitadas atuações de natureza didático-pedagógica destinadas ao Ensino Superior. Ainda que a formação docente necessária ao Ensino Superior exija uma diversidade de estratégias didático-pedagógicas na condução da ensinagem, os PPG em Ciência da Computação apresentam restritas orientações de formação à docência; sendo, portanto, necessária a reflexão sobre as possibilidades de viabilizar a formação docente para atuação no Ensino Superior. Desse modo, pode dizer que ainda é preciso constituir os saberes docentes nas formações de mestrado e doutorado em Ciência da Computação.

Como trabalho futuro será ampliado o corpus da análise para os demais PPG em Ciência da Computação do Brasil, haja vista que esse estudo se limitou aos regimentos e às matrizes curriculares dos 15 PPG de instituições federais de ensino superior das Regiões Norte e Nordeste do Brasil. Além disso, serão realizadas entrevistas com mestrandos, doutorandos e recém ${ }^{10}$ mestres e doutores da área de Ciência da Computação para investigar se e como ocorre(u) sua formação docente na pós-graduação.

\footnotetext{
${ }^{10}$ Serão considerados recém mestres e doutores os diplomados nos último cinco anos a partir de 2018.
} 


\section{Agradecimentos}

Agradecemos ao Grupo de Pesquisa e Extensão em Informática, Educação e Sociedade - Onda Digital (UFBA/CNPq) e à CAPES pelo financiamento parcial desta pesquisa.

\section{Referências}

Anastasiou, L. C. (2007) Ensinar, aprender, apreender e processos de ensinagem. In: ANASTASIOU, L. C.; ALVES, L. P. (Orgs.). Processos de ensinagem na universidade: pressupostos para as estratégias de trabalho em aula. 7. ed. Joinville: Univille, 2007. p. 15-43.

Brasil. (1965) Parecer MEC/CESu no 977/65. Definição dos Cursos de Pós-Graduação. 1965 Disponível em: http://portal.mec.gov.br/cne/arquivos/pdf/2007/parecer\%20cfe\%20977-1965.pdf.

Acesso em: 13 mar. 2018.

. (1996) Senado Federal. Lei de Diretrizes e Bases da Educação Nacional: $n^{o}$ 9394/96. Brasília.

(2007) Lei n. ${ }^{\circ}$ 11. 502, de 11 de julho de 2007. Modifica as competências e a estrutura organizacional da fundação Coordenação de Aperfeiçoamento de Pessoal de Nível Superior - CAPES, [...] e autoriza a concessão de bolsas de estudo e de pesquisa a participantes do programa de formação inicial e continuada de professores para a educação básica. Diário Oficial da União, Brasília, DF, n. 133, 12 jul. 2007.

. (2010) Plano Nacional de Pós-graduação (PNPG) 2011-2020. Disponível em: https://www.capes.gov.br/images/stories/download/PNPG Miolo V2.pdf. Acesso em: 07 jan. 2016.

(2014) Coordenação de Comunicação Social da Capes. Articulação entre pós-graduação e educação básica foi abordada na abertura da terceira semana de Avaliação Trienal. Disponível em: http://www.capes.gov.br/36-noticias/6581-articulacao-entre-pos-graduacao-e-educac ao-basica-foi-abordada-na-abertura-da-terceira-semana-de-avaliacao-trienal. Acesso em: 07 jan. 2016.

. (2015) Portaria $n^{o}$. 086, de 03 de julho de 2015. Aprovar o Regulamento do Programa Nacional de Pós-Doutorado - PNPD. Disponível em: https://www.capes.gov.br/images/stories/download/legislacao/Portaria $862013 \mathrm{Re}$ gulamento PNPD.pdf. Acesso em: 07 jan. 2016.

. (2016) Avaliação Quadrienal da CAPES. Documento de área da Ciência da Computação. Disponível em: http://www.capes.gov.br/images/stories/download/avaliacaotrienal/Docs de area/Ci \%C3\%AAncia da Computa\%C3\%A7\%C3\%A30 doc area e comiss\%C3\%A3o at t08deoutubro.pdf. Acesso em: 07 jan. 2018.

D’ávila, C. M. (2008) Formação Docente na Contemporaneidade: Limite e Desafios. Revista da FAEEBA: Educação e Contemporaneidade, Salvador, v. 17, n. 30, jul/dez. p. $103-112$. 
Ferreira, A. C. C.; Melhor, A.; Barreto, J. S.; Paiva, L. F.; Matos, E. (2015) Experiência prática interdisciplinar do raciocínio computacional em atividades de computação desplugada na Educação Básica. In: Anais do XXI Workshop de Informática na Escola. Maceió/AL. p. 256 - 265.

Freire, P. (1996) Pedagogia da Autonomia: saberes Necessários à Prática Educativa. São Paulo: Paz e Terra.

Imbernón, F. (2004) Formação docente e profissional: formar-se para a mudança e a incerteza. $2^{\circ}$ ed. São Paulo: Cortez.

(2012) Inovar o ensino e a aprendizagem na universidade. Trad. Silvana Cobucci Leite. São Paulo: Cortez.

Massa, M. S. (2015) A formação didático-pedagógica do docente da área de computação: um estudo de caso em uma Universidade Brasileira. In: Anais do XXXV Congresso da Sociedade Brasileira de Computação. Porto Alegre: SBC - Sociedade Brasileira de Computação, 2015.

Matos, E. (2013) Dialética da Interação Humano-Computador: tratamento didático do diálogo midiatizado. Tese (Doutorado em Educação). Universidade de São Paulo, São Paulo/SP.

Identidade profissional docente e o papel da interdisciplinaridade no currículo de licenciatura em computação. Revista Espaço Acadêmico, Maringá, PR, v. 13, n. 148, set. 2013. p. 26 - 34.

Oliveira, V, S.; Silva, R. F. (2012) Ser bacharel e professor: dilemas na formação de docentes para a Educação Profissional e Ensino Superior. Revista HOLOS, ano 28, v. 2. p. $193-205$.

Pimenta, S. G.; Anastasiou, L. G. C. (2014) Docência no Ensino Superior. 5 ed. São Paulo, Cortez.

Pimenta, S. G.; Ghedin, E. (2002) Professor Reflexivo no Brasil: Gênese e Crítica de um Conceito. São Paulo: Cortez.

Ramalho, B. L.; Nuñez, I. B.; Gauthier, C. (2003) Formar o professor, profissionalizar o ensino: perspectivas e desafios. Porto Alegre: Sulina.

Reche; B. D.; Vasconcellos, M. M. M. (2014) A construção da carreira docente por bacharéis: considerações iniciais. In: Anais da X ANPED SUL, Florianópolis. p. 1 20 .

Rivadeneira, A. W.; Gruen, D. M.; Muller, M. J.; Millen, D. R. (2007). Getting our head in the clouds: Toward evaluation studies of tagclouds. In: Proceedings of 25th SIGCHI Conference on Human Factors in Computing Systems. p. 995 - 998.

Santos, E.; Santos, R. (2012) A formação pedagógica é necessária ao docente de computação? - análise dos currículos de referência e das diretrizes curriculares dos cursos da área de computação. In: Anais do XVI Encontro Nacional de Didática e Práticas de Ensino - ENDIPE. Unicamp/Campinas. p. 895 - 908. 
Silva, R. S.; Matos, E. S.; Massa, M. (2018) O desenvolvimento da identidade docente por professores de Computação não licenciados atuantes na Educação Profissional de Nível Médio. XXVI Workshop sobre Educação em Computação. In: Anais do XXXVIII Congresso da Sociedade Brasileira de Computação. Natal/RN. s/p.

Tardif, M. (2012) Saberes docentes e formação profissional. 14 ed. Petrópolis, RJ: Vozes.

Vianna, W. B.; Ensslin, L.; Giffhorn; E. (2011) A integração sistêmica entre pós-graduação e educação básica no Brasil: contribuição teórica para um "estado da arte". Ensaio: aval. pol. públ. educ., Rio de Janeiro, v. 19, n. 71, abr./jun. p. 327-344.

Veiga, I. P. A. (2002) Professor: tecnólogo do ensino ou agente social? In: VEIGA, I. P. A.; AMARAL; A. L. (Orgs.) Formação de professores: políticas e debates. Campinas, SP: Papirus. p. 65 - 96.

Wazlawick, R. S. (2010) Uma Reflexão sobre a Pesquisa em Ciência da Computação à Luz da Classificação das Ciências e do Método Científico. Revista de Sistemas de Informação da FSMA, n. 6. p. 3 - 10 .

Wing, J. M. (2006) Computational Thinking. Communications of the ACM. March, v. 49, n.. 13. p. 33 - 35. 